\title{
Hamlet Brasileiro: ensaio sobre giro linguístico e indeterminação historiográfica (1970-1980) ${ }^{*}$
}

\author{
Brazilian Hamlet: Essay on Linguistic Turn and Historiographic \\ Indeterminacy (1970-1980)
}

\author{
Temístocles Cezar \\ t.cezar@ufrgs.br \\ Professor Associado III \\ Universidade Federal do Rio Grande do Sul \\ Av. Bento Gonçalves, 9500 \\ 91509-900 - Porto Alegre - RS \\ Brasil
}

\section{Resumo}

O objetivo deste ensaio é o de analisar os primeiros efeitos do giro linguístico na historiografia brasileira. Considerando a escassez de pesquisa na área, optei, em primeiro lugar, por fazer uma breve descrição da emergência do giro linguístico em termos mais gerais e, em segundo lugar, uma análise de alguns textos seminais de autores brasileiros que se relacionam, de formas distintas, à temática.

\section{Palavras-chave}

Giro linguístico; Historiografia brasileira; Escrita da história.

\section{Abstract}

This essay aims to analyze the first developments of the linguistic turn in the Brazilian historiography. Considering the shortage of research in this field, I chose to make, first of all, a brief description of the emergence of the linguistic turn in general terms and, then, an analysis of some primary texts of Brazilian authors that relate, in different ways, to this theme.

\section{Keywords}

Linguistic turn; Brazilian historiography; History writing.

Recebido em: 20/2/2014

Aprovado em: 1/7/2014

\footnotetext{
* Este ensaio foi apresentado, de forma embrionária, no $6^{\circ}$ Seminário Brasileiro de História da Historiografia SNHH, realizado em agosto de 2012 no campus de Mariana da UFOP, cujo tema geral foi "O Giro Linguístico e a Historiografia: balanço e perspectivas". Agradeço a gentileza dos meus colegas de mesa-redonda, intitulada "Contextos nacionais e Giro Linguístico: Experiências do tempo, narrativa e Memória" e integrada pelos professores Verónica Tozzi (UBA) e Sérgio Campos Matos (Universidade de Lisboa), e os comentários de Estevão de Rezende Martins, Valdei Lopes de Araujo, Mateus Henrique Pereira e Sérgio da Mata. Tive a oportunidade de discutir o trabalho, um pouco mais desenvolvido, no Laboratório de Teoria e Historiografia da PUC-Rio, em agosto de 2013. Meus agradecimentos aos organizadores e participantes do evento, sobretudo, a Marcelo Jasmin, Ricardo Benzaquen de Araújo, Marcos Veneu e Henrique Estrada. Sou grato também a Edgar de Decca, com quem troquei impressões sobre o assunto em outubro de 2013, na Semana Acadêmica de História da Udesc. Expresso igualmente minha gratidão a Fernando Nicolazzi, Arthur Ávila e Benito Schmidt, colegas de Departamento, e a Alexandre Avelar, pela leitura rigorosa, críticas e sugestões, imprescindíveis para a composição final do texto, cuja pretensão continua a de ser, apesar das suas pertinentes observações, um mapeamento inicial sobre o tema. Finalmente, um agradecimento especial a Flávia Varella e a Bruno Franco Medeiros, incansáveis no apoio "logístico" desde o $6^{\circ} \mathrm{SNHH}$, para a versão final do artigo. Agradeço a Vitor Batalhone Junior pela leitura da versão em inglês deste artigo.
} 
Um tributo a Luiz Costa Lima

"In my view, relativism is the moral equivalent of epistemological skepticism; moreover, I conceive relativism to be the basis of social tolerance, not a license to 'do as you please'" (WHITE 1987, p. 226).

\section{Espectro, relativismo e indeterminação (I)}

$\mathrm{Na}$ introdução à coletânea The return of grand theory to the human sciences, publicada em 1985, Quentin Skinner, prevenia-nos de "ameaças aos fundamentos das ciências humanas", assombradas que estavam pelo "espectro do relativismo epistemológico" (SKINNER 1985, p. 1-20).

Evocação clássica, que adquire reputação maior com Shakespeare, o espectro é a encarnação metafórica dos receios e medos coletivos ou individuais de uma sociedade. ${ }^{1}$ Ao mesmo tempo em que ameaça, ele instaura a dúvida (sobre sua existência, sobre suas intenções). Assim, Marx, ávido leitor tanto dos antigos quanto dos modernos, em particular, do dramaturgo inglês, conjurou-o para a anunciação de um novo tempo no Manifesto: "um espectro ronda a Europa; o espectro do comunismo" (MARX 1848; DERRIDA 1994, p. 19-21).

Depois dele, Paul Valéry flagra outro espectro na sua triste Europa de 1919:

Agora, em um imenso terraço de Elsinor, que vai da Basiléia até Colônia, próximo às areias de Nieuport, aos pântanos do Soma, às gredas da Champagne, aos granitos da Alsácia - o Hamlet europeu olha milhares de espectros. Ele é, porém, um Hamlet intelectual. Medita sobre a vida e a morte das verdades. Tem por fantasmas todos os objetos de nossas controvérsias (VALÉRY 1957, p. 993).

As preocupações condensadas por Skinner, em seu próprio nome e de outros, relacionam-se a um dos desdobramentos vitais para a escrita da história do movimento intelectual que ficou conhecido como "giro linguístico": o fantasma do relativismo, figura gêmea de outro espectro, aquele do ceticismo, cujo limite parece rondar as bordas do irracionalismo. Embora possa parecer, à primeira vista, uma organização disciplinar, tal movimento caracteriza-se pela dispersão de ideias e a ausência de um centro aglutinador que as unifique de fato. Portanto, falar em "movimento" só não se constitui em abuso de linguagem se mantivermos certa tolerância teórica.

Por conseguinte, se todos, de alguma forma, reivindicam, com intensidades diferentes, o legado da linguística de Ferdinand de Saussure ou da filosofia da linguagem de Ludwig Wittgenstein, o alcance do giro linguístico cobre estratos de tempo diversos e espaços - acadêmicos ou não - múltiplos. Seu impacto, seus efeitos ou potencialidades não são facilmente mensuráveis. Cada cultura historiográfica o apropriou a sua maneira, algumas cedendo mais, outras, sem abrir mão de suas idiossincrasias epistemológicas, menos (LA CAPRA; KAPLAN 1982).

Assim, no mesmo ano em que Richard Rorty edita a coletânea The linguistic turn: essays in philosophical method, em 1967, Jacques Derrida publica De la

\footnotetext{
${ }^{1}$ Ver Canto 24 da Odisséia; SHAKESPEARE, William. Hamlet, Ato I, Cena 1.
} 
grammatologie e L'écriture et la différence (RORTY 1967; DERRIDA 1967). A primeira obra insere-se no debate em torno da filosofia analítica como método e é posteriormente negada ou amenizada por Rorty. A segunda e a terceira angariaram, simultaneamente, fortes simpatias e ódios exasperados, que, contudo, não parecem ter abalado seu autor (talvez porque ele desconfiasse fortemente da própria noção autoral, considerando-a mais uma função discursiva do que uma identidade). Enquanto a obra organizada pelo americano se situa em um contexto marcado pelas teses narrativistas que incidem sobre a historiografia (Arthur Danto, cujo livro Analytical philosophy of science é de 1965; os artigos de Louis Mink, "The autonomy of historical understanding", publicado na revista History and theory, em 1966, e "History and fiction as modes of comprenhension", de 1970; e o de William Dray, "On the nature and role of narrative in historiography", que também aparece na History and theory, em 1971), ${ }^{2}$ o francês investe em nada menos do que em uma crítica, segundo ele, à metafísica ocidental e à sua tendência logocêntrica.

A perspectiva anglo-americana obterá um forte impulso no campo da historiografia a partir de 1973, com a publicação de Meta-história, de Hayden White, obra que se tornou referência do "movimento" ao ampliar os interlocutores. Além dos filósofos e críticos literários, agora, mais nitidamente, os historiadores são interpelados (VANN 1998; ANKERSMIT 2001, p. 29). Pessoalmente, considero um equívoco isolar Meta-história do conjunto da obra de White. Um exemplo, entre outros possíveis: no mesmo ano em que publica Meta-história, 142 ele lança também um importante ensaio intitulado "The Greco-Roman tradition", em uma coleção sob sua direção desde 1966 intitulada Major traditions of world civilizations, que passou desapercebido mesmo entre os helenistas e romanistas (WHITE 1973). Tal impressão ficou mais nítida após a releitura de diversos artigos do autor, editados por Robert Doran, que cobrem um período que vai de 1957 a 2007, abrangendo desde um texto sobre "Collingwood and Toynbee: transitions in English historical thought" até a resenha acerca do último livro de Paul Ricœur, A memória, a história, o esquecimento, intitulada de "Guilty of history? The longue durée of Paul Ricœur" (WHITE 2010a).

Trata-se de uma reflexão continuada sobre a história que durante muito tempo foi instigante para alguns (poucos) historiadores e incômoda para (muitos) outros. Esse desconforto parecia decorrer de uma avaliação precipitada: Hayden White, apesar de possuir uma sólida formação histórica, era percebido (e essa percepção não parece ter sido alterada de modo significativo em nossos dias) como um outsider da disciplina no mesmo sentido que Lévi-Strauss o fora nos anos 1950 e 1960. Acusados de atacar a história, o que eles tinham, na realidade, era outro questionário e/ou entendimento acerca do ofício do historiador, o que em alguns casos podia perturbar o sono, fosse ele dogmático ou não. ${ }^{3}$ Nesse sentido, comenta Koselleck no prefácio que faz à tradução alemã de Trópicos do discurso: White não está interessado na história enquanto disciplina, nem na 
escrita da história como um gênero exclusivamente literário; não, ele interroga os historiadores, mantendo uma antiga tradição da retórica, ou para ser mais preciso, os seus textos, e a forma como eles podem mediar socialmente a sua pretensão de verdade (KOSELLECK 2002, p. 38-44). ${ }^{4}$ Ou, nas palavras de Verónica Tozzi, a obra de White "não é um método para os historiadores, mas um alerta contra a ingenuidade da linguagem". ${ }^{5}$ Desse ponto de vista, à versão de que ele não passa de um relativista quase irresponsável, a distância é tão ampla quanto inconsequente. ${ }^{6}$

O famoso e tenso debate entre Carlo Ginzburg e Hayden White situa-se nesse contexto historiográfico (GINZBURG 1992; WHITE 1992). ${ }^{7}$ Mesmo que a resposta a Ginzburg não seja satisfatória, até porque não se tratava de uma réplica, é preciso destacar que Hayden White jamais se furtou ao debate acerca do papel do irracionalismo, do relativismo e do ceticismo na história (WHITE 1992, p. 3753). Antes mesmo de ter publicado Meta-história, em "O fardo da história", de 1966, ele antecipa futuras objeções e refuta a condição de revisionista. ${ }^{8} \mathrm{Em} 1972$, em um pequeno ensaio intitulado "O irracional e o problema do conhecimento histórico no Iluminismo", advertia seus leitores da historicidade dessas categorias, bem como dos seus vínculos com as formas de representar o passado (WHITE 1994, p. 153-167). E, enfim, em Meta-história, White demonstra que a almejada historiografia realista do pensamento histórico do século XIX se caracterizava menos pelo que era de fato e mais pelo que rejeitava em seus predecessores setecentistas, ou seja, "o que mais reprovava na historiografia iluminista era sua ironia essencial, da mesma forma que o que mais reprovava na reflexão cultural era seu ceticismo" (WHITE 1992, p. 61, grifo do autor). ${ }^{9}$

Já a releitura ou a desconstrução de Derrida refluirá não apenas em solo francês como nos próprios Estados Unidos. A linguagem que visa, inicialmente, não apenas a invadir, mas também a fraturar a lógica dos chamados grandes

\footnotetext{
${ }^{4}$ Essa obra é, por sua vez, prefaciada pelo próprio Hayden White.

${ }^{5}$ Conferência pronunciada no $6^{\circ}$ Seminário Brasileiro de História da Historiografia - SNHH, "O Giro Linguístico e a Historiografia: balanço e perspectivas". Nesse mesmo sentido, ver também a introdução que Tozzi escreve para a coletânea de artigos de White intitulada: Ficción histórica, historia ficcional y realidad histórica (WHITE 2010b, p. 13-29).

${ }^{6}$ Nesse sentido, a recente tese de Herman Paul pode ser considerada uma tentativa de romper com essa visão empobrecedora da obra de White (PAUL 2011). Pedro Spinola Caldas, na excelente resenha que faz do livro de H. Paul, não deixa de destacar esse aspecto (CALDAS 2013, p. 277).

7 Ginzburg, antes e após o debate nos EUA, unilateralmente, já havia desenvolvido o tema em vários outros textos (GINZBURG 1989, p. 178-20; 1989, p. 44-45; 1997, p. 16-24). Outros autores participaram desse debate de modo intermitente. Seria desmesurado listá-los neste espaço. A já citada obra de Herman Paul oferece uma abordagem que analisa os efeitos dessa discussão, em um subcapítulo de sua tese sugestivamente intitulado "specter of fascism" (PAUL 2011, p. 119-124). François Hartog e Francisco Murari Pires, também mais recentemente, dedicaram-se à compreensão das críticas de Ginzburg a White, ainda que adotando perspectivas distintas (HARTOG 2011; PIRES 2013).

8 "A metáfora que rege um relato histórico poderia ser tratada como uma norma heurística que elimina autoconscientemente certos tipos de dados tidos como evidência. Assim, o historiador que opera segundo essa concepção poderia ser visto como alguém que, a exemplo do artista e do cientista moderno, busca explorar certa perspectiva sobre o mundo que não pretende exaurir a descrição ou a análise de todos os dados contidos na totalidade do campo dos fenômenos, mas se oferece como um meio entre muitos de revelar certos aspectos desse campo. [...] O resultado dessa atitude não é o relativismo, mas o reconhecimento de que o estilo escolhido pelo artista para representar uma experiência interior ou uma exterior traz consigo, de um lado, critérios específicos para determinar quando uma dada representação é internamente consistente e, de outro, fornece um sistema de tradução que permite ao observador ligar a imagem à coisa representada em níveis de objetivação" (WHITE 1994, p. 59, grifo do autor).

${ }^{9}$ Em relação à história do ceticismo, ver o excepcional estudo de Richard Popkin (2003). Para uma abordagem mais diretamente da história, ver MUNSLOW 2010, p. 62-77.
} 
relatos das ciências sociais, descentralizando a ideia da verdade como um valor universal e, na sua ausência, ou na inexistência de um núcleo ou de uma origem de definições, tornar tudo discurso adquire legitimidade acadêmica e institucional (o que não significa falta de crítica: basta ver, em relação a Derrida, por exemplo, a crítica devastadora de John Searle de 1990, que não ficou sem réplica) (SEARLE 1991).

Porém, seria ilusório achar que os franceses fecharam um acordo "nacionalista" em torno da relação entre história, linguagem, texto, narrativa ou discurso. Vejamos algumas datas: em 1967, Roland Barthes publica um pequeno artigo intitulado "Le discours de I'histoire" que rapidamente torna-se uma referência incontornável. ${ }^{10} \mathrm{Em} \mathrm{1971,} \mathrm{aparecem} \mathrm{Comment} \mathrm{on} \mathrm{écrit}$ I'histoire: essai d'épistémologie, de Paul Veyne, e a aula inaugural no Collège de France de Foucault, L'ordre du discours. Ambos são alvos de ácidas críticas de outro francês que também se torna conhecido pelo uso criativo da linguagem da e na história, Michel de Certeau (a crítica ao primeiro dos autores aparece nos Annales: "Une épistémologie de transition: Paul Veyne", em 1972; e, a endereçada ao segundo, em 1973, em "Le noir soleil du langage par Michel Foucault", L'absent de l'histoire); ainda em 1973, Régine Robin publica Histoire et linguistique, obra mais voltada para a metodologia da análise do discurso marcadamente francesa. Em 1974 surge Faire de l'histoire, coletânea dirigida por Jacques Le Goff e Pierre Nora, em três volumes, obra importante por abrir novas perspectivas de análise nas quais a linguagem ocupa um lugar de destaque, apesar de nela não haver nenhuma menção aos narrativistas americanos (muito menos a Hayden White, cuja obra, naquela época, como ainda hoje, não contava com uma tradução para o idioma francês $)^{11} \mathrm{e}$, praticamente, nenhuma gota de Paul Ricœur. Por último, em 1975, aparece L'écriture de l'histoire, de Michel de Certeau. ${ }^{12}$ De fato, se há ou houve uma terceira geração dos Annales - A nova história francesa - cuja produção teria reduzido a história, de acordo com um dos seus detratores de primeira hora, a "migalhas", então seria preciso reavaliar se não é a própria noção de escola que se esfacela (DOSSE 1987). ${ }^{13}$

\footnotetext{
${ }_{10}$ Apesar de, nele, Barthes simplesmente propor o apagamento da narrativa! (BARTHES 1984, p. 164). Esse "detalhe" não escapou a François Hartog em obra recente (HARTOG 2013, p. 115-116).

${ }_{11}$ Isso não significa a falta de recepção da obra. Por exemplo, nos volumes I e III de Temps et récit, Ricœur ocupa-se dos trabalhos de Hayden White, sobretudo de Meta-história (RICEUR 1983, p. 286-301; 1985, p. 272-280).

${ }_{12}$ As referências completas dessas obras estão na bibliografia.

${ }^{13}$ No prefácio à segunda edição publicada dez anos depois, em 1997, Dosse relativiza consideravelmente suas críticas (ver 2a. ed., p. I-VIII). Antes dele, François Furet já observava que "para falar a verdade, não há, desde a origem [dos Annales] escola de pensamento", mas hegemonia de influência e de reputação (FURET 1982, p. 5-9). E em um misto de ironia e humor, em uma entrevista, arremata: "Eu sempre digo brincando que a École des Annales não tem outra definição, senão a de que ela é as pessoas que eu encontro de manhã no elevador. $\mathrm{O}$ que existe de comum entre Le Roy Ladurie, Le Goff, eu, Richet etc.? Como podem nos identificar sob uma mesma etiqueta?" ("Entrevista de François Furet concedida a Aspásia Camargo"; CAMARGO 2003, p. 69). De fato, muitos franceses consideram que não houve na França giro linguístico, mas um "tournant critique", proveniente de dois editoriais publicados nos Annales ("Histoire et sciences sociales. Um tournant critique?", Annales, 2, mars-avril, 1988, p. 291-293; "Histoire et sciences sociales: tentons l'expérience", Annales, 6, novdéc., 1989, p. 1317-1323). Para um mapeamento desse movimento e suas diferenças com o giro linguístico, ver o trabalho de Gérard Noiriel. A principal diferença é que a versão francesa do giro continuaria fiel a um pressuposto básico dos Annales: o estudo da sociedade; parece-me que essa peculiaridade mereceria uma argumentação mais desenvolvida (NOIRIEL 1996, p. 150-154). No mesmo sentido, para Christian Delacroix, o "tournat critique" pode ser interpretado como uma das respostas da história social, criticamente leal à tradição dos Annales, aos desafios do giro linguístico (DELACROIX 2010, p. 484-485).
} 
Contudo, meu propósito é menos o de naturalizar uma cronologia do giro linguístico, como se fosse um a priori epistemológico, do que tentar demonstrar que ela é uma construção que ocorre nos anos 1960 e 1970 para os filósofos e críticos literários anglo-saxões e, a posteriori, para boa parte dos historiadores. Não parece outra a razão do sucesso do artigo de Laurence Stone, "The revival of narrative: reflections on a new old history", publicado na revista Past and present em 1979.

Aqui o conceito de narrativa remete para outro campo semântico que, embora possa ter se originado em uma atmosfera na qual os estudos sobre a linguagem tenham algum valor diferenciado, sustenta-se a partir de uma noção muito frágil: "a narrativa é a organização de materiais em uma ordem sequencial cronológica e a concentração do conteúdo em uma única história coerente" (STONE 1974, p. 19). Seu suposto retorno seria uma consequência da desilusão de parte da comunidade dos historiadores com a história econômica e social. Amparada na emergência de uma história das mentalidades voltada para os sentimentos, emoções e padrões de comportamento, logo mais antropológica e, consequentemente, mais atenta as suas formas de transmissão, a narrativa seria o vetor dessa nova ou outra história.

Não quero subestimar, nem superestimar, o artigo de Stone, que me parece mais importante pelo debate que suscitou do que pela sua consistência interna. Houve quem se identificasse com suas ideias, quem o refutasse e quem simplesmente o ignorasse, mas o historiador informado sabia da sua existência. Não é surpreendente que o revival da narrativa se faça acompanhar de tantos outros retornos, nem que ressurja com força nosso espectro - o relativismo -, desta feita, dos novos objetos, das novas abordagens, das novas perspectivas (a tríade de Faire l'histoire convertida em palavras de ordem dessa autointitulada nova historiografia).

A fim de não alongar esta breve contextualização, proponho um salto até as considerações de despedida da historiadora Gabrielle Spiegel do cargo de presidenta da American Historical Association, em 2009. Nessa conferência, intitulada sugestivamente "The task of the historian" (impossível não relacionar com a conferência de Humboldt de 1821!), os limites e potencialidades do giro linguístico são oficialmente expostos: "a crença - afirma a autora - de que a linguagem é a agente constitutiva da consciência humana e da produção social de sentido, e que nossa apreensão do mundo, tanto passado quanto presente, só é obtida através de percepções pré-codificadas pela linguagem" é o "desafio semiótico" que foi colocado para a historiografia nas últimas décadas. Ela analisa a contribuição de Richard Rorty, seu progressivo desânimo com a máquina de guerra que criara, avalia o que nomeia como "as possíveis raízes psíquicas do giro linguístico", e, assim, encontra argumentos para justificar a postura de Derrida como efeito inexorável da sua condição de filho de judeus franco-argelinos e da "consciência inescapável do Holocausto" (SPIEGEL 2009).

Para Spiegel, não seria difícil estabelecer um paralelo entre a psicologia do giro linguístico e os princípios básicos do que chama de pós-estruturalismo: "o sentimento de que a vida é um traço, assombrada por uma presença ausente; 
seu sentido de indeterminação; uma crença na indecibilidade final da linguagem (sua aporia, no sentido de Derrida)"; ou seja, a dificuldade de falar e representar o indizível, na mesma perspectiva de Dominick La Capra.

A historiadora, por fim, se pergunta para onde caminha a história pósgiro linguístico? Baseando-se em Nancy Partner, para quem a história entrou em um período pós-pós-moderno, Spiegel argumenta que "é improvável que retornemos ao 'realismo quase-científico', à 'empiria ingênua' ou a qualquer dos postulados pré-pós-modernos que informavam a escrita da história". Também não é provável que a maior parte dos historiadores vá responder "ao chamado a uma 'experiência histórica sublime' recentemente feito por F. R. Ankersmit". O mais provável, segundo ela, desta vez seguindo Michael Roth, é que os temas preponderantes da agenda historiográfica não deixem de incluir questões como a "ética, pós-colonialismo, império, cosmopolitismo, traumas e os animais" (SPIEGEL 2009). Todos esses temas têm em comum a tentativa de restaurar uma conexão mais direta e imediata com o passado ou com algum aspecto central da experiência que não passe necessariamente pela preponderância da linguagem.

Finalmente, da desconstrução de Derrida, Spiegel guarda a fórmula, por vezes enigmática, de apreender e de escutar os silêncios da história a partir de narrativas fragmentadas:

vivemos em um momento de grande instabilidade e incerteza cultural. Enquanto historiadores, nós lutamos para conhecer o ausente e o outro, para afirmar um direito à palavra e à fala. Como Derrida, estamos "tentando escrever a questão: (o que) isto quer dizer?". Precisamente, ainda não está totalmente claro quais instrumentos iremos utilizar na busca por nossos labores históricos. Mas insisto em acreditar que há algo que a desconstrução nos ensinou de forma mais poderosa do que qualquer estratégia de leitura que conheço: escutar o silêncio (SPIEGEL 2009).

Não poderiam esses silêncios significar, pergunto eu, uma sombra ou um efeito do nosso espectro, agora com quase 40 anos? Ou simplesmente uma possível forma de comprovar o ambiente de indeterminação do saber histórico quando relacionado às provocações do giro linguístico ${ }^{14}$

\section{O espectro ronda os marxistas}

Optei por iniciar a análise pelo que chamo de os "primeiros efeitos" do giro linguístico na historiografia brasileira. Seria prematuro falar de "impacto", possibilidade de recepção que parece requerer não apenas uma maior quantidade de dados sociológicos, mas também uma duração mais ampla. ${ }^{15}$ Esses desdobramentos

\footnotetext{
${ }_{14}$ Não quero com isso situar Spiegel em um contexto que não Ihe pertence, ou ligá-la a uma afiliação que ela não reivindica. Em um artigo de 1992, a historiadora assumia a postura de "mediação", reconhecendo, simultaneamente, a crença na realidade do passado e o fato de a história ser um discurso escrito, ou seja, de que a linguagem reconstrói o objeto (SPIEGEL 1992). Para uma análise mais aprofundada dessa posição de Spiegel, ver o livro de Alun Munslow (1997, p. 106-107). A propósito disso, o livro de Munslow desvela com rigor teórico o debate entre empiristas, reconstrucionistas e desconstrucionistas (não no sentido de Derrida, como explica o autor na p. 2) que tem por tema de fundo a discussão sobre as formas de objetivação do conhecimento histórico e suas figuras gêmeas, entre as quais se destaca a questão do relativismo.

${ }^{15}$ Agradeço a Fernando Nicolazzi por ter-me chamado a atenção para esta importante distinção, nem sempre
} 
iniciais ocorreram em um momento difícil e potencialmente rico da história política do país: o fim da ditadura civil-militar. No Brasil, como em outros países, ele produziu simultaneamente querelas e brechas teóricas. Querelas de todas as ordens - ideológicas, epistemológicas, estéticas etc. - instauraram-se em vários campos de pesquisa e áreas de ensino, desde os mais consolidados àqueles em formação, gerando entendimentos díspares ou simples preconceitos acadêmicos. Se fosse me servir de uma imagem para representar essas disputas a litografia de M. C. Escher, Relatividade, de 1953 (Figura 1), não seria um disparate. ${ }^{16}$

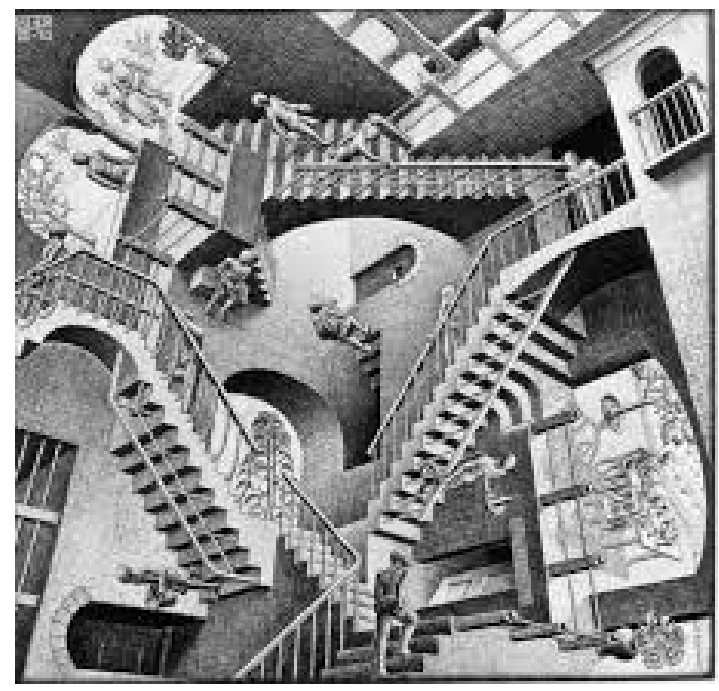

Figura 1 - M.C. Escher, Relatividade, 1953.

A recepção, de modo geral, foi basicamente dos franceses, com um ou outro infiltrado, como Laurence Stone e, um pouco mais tarde, Carlo Ginzburg. Ressalte-se que a obra de Derrida, neste momento, foi praticamente ignorada pelos historiadores (e, parece-me, com justas ou injustas razões, continua sendo, salvo raras exceções), em contraposição ao já citado artigo "Le discours de l'histoire" de Roland Barthes, também de 1967, que, com pouco mais de dez páginas, causou mais "efeito". De fato, os conflitos e as diferenças de além-mar foram praticamente subsumidos em uma nova e abrangente identidade: a "teoria" da nova história, mais precisamente, a história das mentalidades.

Os historiadores marxistas (o campo e a área mais consolidados) revoltaram-se contra a tendência que se insinuava. Além da denúncia da fragmentação temática e teórica, existia o risco de o inevitável relativismo, consequência inexorável do abandono das "totalidades sociais significativas", conduzir à irracionalidade epistemológica e à letargia política. Embora tenha havido respostas mais sofisticadas, como a de Sérgio Paulo Rouanet, entre os historiadores, preponderaram análises menos densas mas, certamente, mais impactantes (ROUANET 1987, p. 124-146). 
Ciro Flamarion Cardoso foi quem assumiu a posição de porta-voz e defensor dos perigos que essas "distorções ou inversões radicais de perspectivas" significariam para a historiografia. Em seus Ensaios racionalistas, de 1988, "sem ocultar" sua "oposição radical a uma 'Nova História' que se [Ihe] afigura uma corrente retrógrada sob aparências de novidade e ousadia", ele apresenta seus riscos e/ou erros: "1. a valorização do periférico em relação ao central; ${ }^{17} 2$. valorização, não da realidade social, das condições reais de existência, e sim do seu avesso - sonhos, imaginário, ideologias; ${ }^{18} 3$. o tecnicismo que valoriza - computador e outras técnicas de vanguarda oculta uma grande pobreza metodológica" (CARDOSO 1988, p. 94). ${ }^{19}$ Em suma, a Nova História tem uma função ideológica poderosa: conquanto não se trate de uma "apologia aberta do capitalismo", mas de uma "forma bem mais sutil" de apoio, "uma vez eliminados o racionalismo e em especial o marxismo, o que permanece, embora isto não se diga, é o próprio capitalismo - e uma série de concepções que não o incomodam" (CARDOSO 1988, p. 101).

Nessa primeira abordagem, embora Cardoso reconheça a validade dealgumas temáticas "que são em muitos casos pertinentes e solicitadas pelo momento atual" (CARDOSO 1988, p. 114), desde que adequadamente trabalhadas, a sua crítica ainda é muito difusa: trata-se de um ataque generalizado a quase toda a produção recente que não seja orientada pelo marxismo. Não há, por exemplo, uma aproximação entre Nova História, pós-estruturalismo ou pós-modernidade, como na sequência se notará, e muito menos uma demonstração do que seria o irracionalismo, em termos de teoria ou filosofia da história, de tais tendências. ${ }^{20}$

Com esse propósito, em 1989, Michel Zaidan Filho, publica A crise da Razão histórica, coletânea de textos que visam a esclarecer "o papel do marxismo - enquanto teoria da história" e "a significação da sua atual crise" (ZAIDAN 1989, p. 15). Produto do Iluminismo e da razão moderna, o pensamento de Marx estaria acuado por "novas metodologias" marcadas pelo "fragmentário, o micrológico, o particular, o fortuito, o imaginário, o sexo etc." e cujo resultado para a "cultura brasileira" seria o surgimento de "um novo surto de irracionalismo" (ZAIDAN 1989, p. 16, 19). A matriz filosófica dessa doença epistemológica é, segundo o autor, "um certo neo-nietzschianismo" provocado, sobretudo, pela obra de Michel Foucault e pela "sociedade pós-moderna" (ZAIDAN 1989, p. 19-20). A concepção irracionalista da história fundamenta-se assim em uma "desreferencialização do real, operada pela ação da mídia, ao reduzir tudo ao

\footnotetext{
17 "Preferem-se, como objetos de estudo, os loucos, os marginais, os homossexuais, as bruxas, as prostitutas (ao sabor, na verdade, de modismos descartáveis)" (CARDOSO 1988, p. 100). É curioso que não seja citado aqui o importante estudo de Laura de Mello e Souza que reivindica claramente para si a inserção no campo da história das mentalidades (SOUZA 1986).

18 "Numa 'leitura' que analisa o discurso verbal ou não-verbal (iconografia, por exemplo) partindo do princípio de um divórcio da evolução ideológica em relação à econômico-social; tematicamente, pululam as danças macabras, as 'pulsões reprimidas do desejos', os sabbats, os fantasmas e obsessões, e é frequente o anacronismo na forma de projeção de percepções atuais feitas em função da sociedade de hoje (feminismo, 'problema gay') a épocas em que eles carecem de qualquer sentido ou realidade" (CARDOSO 1988, p. 100). 19 "As fontes são escolhidas em forma arbitrária, tratadas sem rigor, usadas de maneira pouco crítica e racional" (CARDOSO 1988, p. 100).

${ }^{20} \mathrm{Em}$ trabalho anterior, destinado a um público estudantil, publicado em 1981, Ciro F. Cardoso deixa entrever sua reserva em relação à chamada Nova História com críticas endereçadas exclusivamente a Paul Veyne (CARDOSO 1981, p. 10-11, 39).
} 
simulacro, à simulação, à representação da realidade" (ZAIDAN 1989, p. 21). Paralelamente, a pós-modernidade gera uma "dessubstancialização do sujeito que afeta, de acordo com o autor, diretamente a teoria da história -, reduzido a um mero feixe de sensações hedonistas, administradas pela sociedade de consumo" (ZAIDAN 1989, p. 22).

Tal como Ciro Cardoso, Zaidan Filho preocupa-se com a recepção dessa moda pela historiografia brasileira e sua relação com o contexto político. Atuando em uma nação atrasada em relação aos países capitalistas desenvolvidos, vivendo a transição da ditadura para um regime mais aberto, os historiadores brasileiros estariam sendo presa fácil de um debate que se iniciara, tempos antes, nos EUA e na Europa sob a égide da "moderna e sofisticada indústria cultural: assim, não são de surpreender os rumos anti-iluministas, anti-intelectuais, enfim, anti-racionalistas que vem assumindo o debate cultural da 'Nova República'"' (ZAIDAN 1989, p. 23).

Ele cita como exemplos, a produção de dissertações de mestrado e de estudos que reclamam "o pensamento" de Foucault, de "um certo Foucault, aquele pós-estruturalista", precisa o autor. A bem da verdade, os únicos historiadores brasileiros dignos de menção nominal, neste capítulo, em duas breves notas de rodapé, são Nicolau Sevcenko, cujo livro Literatura como missão, de 1983, seria uma demonstração da recepção equivocada de Walter Benjamin, principalmente do "conceito de crítica benjaminiano", e Edgar de Decca, que, em seu O silêncio dos vencidos, de 1981, teria ido "longe demais numa apologia orgiástica do sentido, da desrazão" (ZAIDAN 1989, p. 25; SEVCENKO 1983; DECCA 1981). ${ }^{21}$ As pré-noções e uma boa dose de leviandade acadêmica não impedem, contudo, que Zaidan Filho reconheça que "não se pode mais ignorar os limites irracionais e ideológicos do discurso político ou teórico" (ZAIDAN 1989, p. 25). A solução, no entanto, não estaria no abandono da razão "como tal", mas na construção de outro paradigma racional: a "razão comunicativa", afirma o autor (sem citar Habermas!). ${ }^{22}$

Além do certo Foucault, Zaidan Filho salienta que a historiografia brasileira vivia sob a influência de uma miríade de novidades temáticas - "frequentemente com projeções anacrônicas de questões bem atuais sobre o passado longínquo" (ZAIDAN 1989, p. 23, grifo do autor) - oriundas da "Nouvelle histoire". Ele cita nominalmente apenas um desses historiadores que provocam o "fascínio pelo brilho dos temas não usuais, heterodoxos", a fim de fazer "justiça", pois é preciso distinguir, ainda segundo Zaidan Filho, "autores como Ginzburg ou Vovelle e aqueles como Philippe Ariès" (ZAIDAN 1989, p. 23-24).

Para sustentar sua tese, ele busca apoio nos Ensaios racionalistas, com uma ressalva: "sua abordagem [a de Ciro Cardoso] se ressente, contudo, da falta de uma teoria articulada da crise da modernidade. Daí o apego e a reiteração de velhos pressupostos: o materialismo dialético, a teoria do reflexo, a teoria dos modos de produção etc." (ZAIDAN 1989, p. 24, grifo do autor). Seja como for,

\footnotetext{
${ }^{21}$ Ambos os estudos foram apresentados originalmente como teses de doutorado. Mais adiante, no artigo intitulado "Imaginário e História", Zaidan Filho volta a citar Sevcenko e de Decca, acrescentando as historiadoras Margareth Rago (1985) e Maria Clementina Pereira Cunha (1987). O autor apontava, como crime das autoras, a influência de Foucault e da "Nouvelle histoire" (ZAIDAN 1989, p. 39).

22 É justo dizer que ele o cita no artigo seguinte (ZAIDAN 1989, p. 27).
} 
o leitor fica sem entender o porquê de ter de realizar tal distinção, ou seja, de saber qual a diferença entre os dois primeiros e Ariès. ${ }^{23}$ De fato, o historiador italiano parece ser um modelo do novo e correto historiador, uma vez que é capaz de realizar a "reconstrução analítica da diferença entre o passado e o presente, tal como fez estudando a mentalidade de um moleiro medieval", investigação na qual o autor faz uma "dura e pertinente crítica ao 'irracionalismo' estruturalista de M. Foucault" (ZAIDAN 1989, p. 74).

Diferentemente de Ciro Cardoso, Zaidan Filho apresenta-se ao mesmo tempo como um crítico do marxismo ortodoxo e como um interlocutor dos "novos" historiadores que não violentem a razão moderna. ${ }^{24}$ No entanto, sua análise não deixa claro o que exatamente o incomoda em termos teóricos e mesmo políticos, nem, enfim, qual seria o grande mal que se dissimularia por trás do que chama de relativismo ou de irracionalismo. ${ }^{25}$ Permaneceríamos em uma espécie de limbo epistemológico?

Carlos Fico e Ronald Polito, em trabalho de fôlego no qual procuraram mapear a produção historiográfica brasileira de 1980 a 1989, diagnosticaram essa ausência de conexão. A suposta crise da razão e suas contrapartidas pecam pelos "elos" frágeis: "a compreensão sobre o que seja a parte 'irracional' da História é sempre muito mal explicada". Para eles, a subjetividade inerente a certos temas (a história do cotidiano, por exemplo) não é facilmente explicada por "uma razão científica que suponha determinações macroestruturais". Por outro lado, isso não significa que os acontecimentos que se passam no dia a dia e que estão, portanto, sujeitos a condicionantes subjetivos "estejam definitivamente entregues a um mundo caótico e ininteligível de contingências" (FICO; POLITO 1992, p. 168). ${ }^{26}$ Os autores identificam na falta de operadores conceituais e metodológicos e no "desapego à teoria por parte dos historiadores no Brasil", seja marxistas ou

\footnotetext{
23 Philippe Ariès volta a ser citado como referência incômoda no capítulo 5 - "O novo olhar do historiador" -, junto com Paul Veyne (ZAIDAN 1989, p. 72, 74). Por outro lado, Jacques Le Goff é poupado por criticar o "esfacelamento da sociedade" em certas investigações sobre o cotidiano (ZAIDAN 1989, p. 73).

${ }^{24}$ Embora o assunto escape a meu escopo neste momento, é preciso registrar que Ciro Cardoso, anos depois, em 1997, procura remediar este vazio na introdução a uma obra coletiva organizada em conjunto com Ronaldo Vainfas. Nela, o historiador sintetiza o debate entre dois grandes paradigmas: o iluminista e o pósmoderno. Enquanto o primeiro se caracteriza pelo bom uso da razão, o segundo é marcado e atravessado por posturas "céticas e irônicas", pelo "culturalismo relativista", pelo "método hermenêutico relativista", pelo "subjetivismo", "irracionalismo", "misticismo", enfim por um "império exclusivo do relativismo e da microanálise" (CARDOSO; VAINFAS 1997, p. 1-23). Ressalte-se, contudo, que o mérito do livro é não restringir a participação de um ou outro autor em função de sua suposta posição em relação a esses dois paradigmas. Nesse sentido, ver a ponderada conclusão de Ronaldo Vainfas intitulada "Caminhos e descaminhos da História" (CARDOSO; VAINFAS 1997, p. 441-449). Em 2012, os mesmos autores editaram os Novos domínios da História (CARDOSO; VAINFAS 2012). A introdução intitulada "História e conhecimento: uma abordagem epistemológica", a cargo de Ciro Cardoso, centra-se nas "modalidades básicas ou principais da epistemologia da história", subdivididas em três: reconstrucionismo (principalmente, concepções "empiristas" do século XIX); construcionismo (marxismo, weberianismo e "Escola" dos Annales); desconstrutivismo (basicamente, exemplificadas com Hayden White e Paul Veyne) (CARDOSO; VAINFAS 2012, p. 1-19). Mais uma vez, Ronaldo Vainfas, de modo elegante, faz o contraponto necessário na conclusão - "Avanços em xeque, retornos úteis" -, relativizando certos argumentos muito gerais de Ciro Cardoso (CARDOSO; VAINFAS 2012, p. 319-335). Além disso, é necessário acrescentar que, em 2005, Ciro Cardoso volta a atacar a "virada linguística" e a "desconstrução" baseando-se em um trabalho de David Carr (1991) no qual Hayden White e Hans Kellner são definidos como historiadores que negam a "existência, lá fora, de uma história que precise ser contada" (CARDOSO 2005, p. 64-66).

${ }^{25}$ Para uma análise mais ponderada, ver as "interrogações" de Sílvia Petersen (1992a, p. 108-126).

${ }^{26}$ Referência válida para as outras citações deste parágrafo. Na mesma conjuntura e especificamente acerca da história do cotidiano, Sílvia Petersen dedica uma série de artigos sobre o tema procurando cercá-lo em termos teóricos e metodológicos (PETERSEN 1992b, p. 108-126; 1993, p. 41-55; 1994, p. 112-125; 1995, p. 30-39).
} 
adeptos de outras correntes historiográficas, fatores decisivos para o debate travado em termos tão insuficientes (FICO; POLITO 1992, p. 170-175). ${ }^{27}$

\section{Espectro, relativismo e indeterminação (II)}

Uma história da historiografia atenta a movimentos intelectuais de descontinuidade não poderia deixar de notar que, apesar de tudo, houve tentativas de reflexões teóricas mais apuradas e críticas desse novo "bando de ideias novas" (certamente não tão novas como as que povoaram a geração de Sílvio Romero). É em função dessa possibilidade analítica que penso que o "impacto" do giro linguístico foi igualmente uma brecha, um gap no sentido que Ihe atribui Hannah Arendt, ou seja, um "estranho entremeio no tempo histórico, onde se toma consciência de um intervalo no tempo inteiramente determinado por coisas que não são mais e por coisas que não são ainda" (ARENDT 1992, p. 35-36).

Como ainda não temos um levantamento exaustivo da recepção do giro linguístico pela historiografia brasileira, optei por restringi-lo a alguns estudos seminais da década de 1980, sem ter o objetivo de fixar ou de determinar um começo ou uma origem nem querer com isso atribuir a esses estudos um estatuto que eles não reivindicavam nem se autoatribuíam; não por temor do anacronismo, mas por respeito intelectual.

A partir dessas considerações retomo aqui, sinteticamente, o texto de Luiz Costa Lima apresentado no "Colóquio Narrativa: ficção e história", realizado no Rio de Janeiro em novembro de 1987. Em seu trabalho, intitulado "Clio em questão: a narrativa na escrita da história", Costa Lima congrega, de modo até então inusitado, as concepções provenientes dos narrativistas anglo-americanos, com Hayden White, bem como da historiografia francesa, suas relações com a antropologia de Lévi-Strauss e com a obra de Paul Ricœur (LIMA 1988, p. 63-89). ${ }^{28}$

Interessa-me aqui a apropriação que faz Costa Lima da obra de White. Sem descartar inteiramente a Meta-história, o centro da crítica do brasileiro privilegia dois artigos publicados por White na primeira metade dos anos $1980 .{ }^{29}$ Discutindo a questão da distinção entre a narrativa histórica e a ficcional e a função de prefácios em um ou outro gênero por W. Dray, cuja análise teria sido prejudicada pelo exemplo escolhido, Costa Lima busca em White uma alternativa que "constituíra a hipótese de que toda a narrativa, desde o conto folclórico até o romance, supõe uma busca de ordenação, a partir de uma lei socialmente configurada" (LIMA 1988, p. 77).

Em consequência, a escrita de anais históricos no medievo, mencionada por White, seria um problema, não necessariamente uma objeção à tese narrativista. Costa Lima desloca o caso a fim de apresentar duas "soluções": 1. considerando que a narrativa não encontra obstáculo na Antiguidade clássica, "deveríamos dizer

\footnotetext{
27 Em 1997, Carlos Fico ainda lamentava a indiferença de boa parte dos historiadores em relação à reflexão teórica (FICO 2000, p. 27-40).

28 A contribuição alemã para a discussão sobre as relações entre história e narrativa não era, segundo explica Costa Lima em uma nota, central, embora ele não deixe de observar a importância de dois livros que mereceriam atenção: um de K. Enlich, de 1980, sobre a narrativa do cotidiano e, principalmente, outro, sobre a teoria da história, organizado por R. Koselleck e J. Rüsen (LIMA 1988, p. 68).

29 "The value of narrativity in the representation of reality" (Critical inquiry, 1980) e "The question of narrative in contemporary historical theory" (1984, History and theory), ambos reproduzidos em WHITE 1987.
} 
que a tese não tem alcance universal porque a ordenação de princípio-meio-fim não se aplica aos exemplos medievais"; 2. em contraposição, se a ideia de lei social é elemento indispensável à ordenação narrativa, então os anais medievais estariam excluídos, pela análise de White, do âmbito da narrativa histórica. Faltariam a eles os conectores de linguagem necessários à estrutura da narração e estabelecidos por um centro social de poder. Costa Lima lembra que a ausência de Estado na Idade Média não significava anomia: "a comunidade humana ali se organizava em torno de uma lei que, inescrutável, impunha a impossibilidade de conexões causais explicativas dos eventos do mundo" (LIMA 1988, p. 78). Logo, por um lado, Costa Lima está de acordo com a ideia de que a narrativa histórica se relaciona notadamente com a instância política de uma dada sociedade e, por outro, e pela mesma razão, discorda de que os anais e crônicas medievais escapem da dimensão narrativa pela "ausência de qualquer consciência de um centro social", como parece sugerir White (LIMA 1988, p. 77).

Para Costa Lima, "a posição de White não se inclui simplesmente na dos narrativistas; ao invés, abre uma sucursal divergente". Segundo o autor, "os narrativistas falhariam por ver a escrita da história como determinada a fornecer apenas informações e, por conseguinte, por não suspeitarem de sua proximidade com a literatura". Contudo, ele percebe em White - e isso não era fácil de ser percebido nos anos 80 (nem hoje) - que "a bem da verdade deve-se acrescentar que White não pretende estabelecer uma identidade absoluta" entre história e literatura. Para ele, continua Costa Lima, "a narrativa histórica assim não trata de objetos ficcionais senão que aborda eventos reais, configurando-os com a ajuda das formas ficcionais vigentes em uma cultura" (LIMA 1988, p. 85). ${ }^{30}$

Não obstante, ele não concorda com certas premissas de White (o exemplo para a discordância é a análise que o americano realiza do 18 Brumário de Marx, iniciada em Meta-história). ${ }^{31}$ Apesar do desacordo, para Costa Lima,

é inegável que sua reflexão [de White] é considerável para os interessados em melhor especificar os estatutos da história e da ficção. Por força da pressão em favor de uma história científica, os historiadores têm genericamente descurado o papel que, em seu trabalho, desempenha o imaginário e, pelo temor de se afastarem da "objetividade", têm desperdiçado parte da riqueza de seu material (LIMA 1988, p. 85-86).

Eis que, mais uma vez, o espectro que nos ronda ressurge; no entanto, partindo de Costa Lima, não parece tão assustador. ${ }^{32}$

Coube a Ricardo Benzaquen de Araújo o comentário ao texto. Ele concentra-se na relação entre narrativa histórica e ficção. Para tanto,

\footnotetext{
${ }^{30}$ Referência para todas as citações do parágrafo.

${ }^{31}$ Infelizmente, por uma questão de espaço, não retomarei aqui a ainda procedente crítica de Costa Lima à abordagem de White acerca do 18 Brumário de Marx. A divergência gira em torno do tema da "farsa" e da constituição do fato histórico. Apenas ressalto que também seria interessante e possivelmente produtivo considerar a temática a partir da figura da imitação.

32 A análise da chamada "Trilogia do controle", publicada na década de 1980, bem como o acerto de contas de Costa Lima com o debate sobre a história e os gêneros ficcionais, publicado em 2006, seriam, importantes para uma avaliação mais pormenorizada do impacto e importância destas questões, porém, em termos práticos, são inviáveis no espaço de um simples artigo (LIMA 2006; 2007).
} 
reconstitui o argumento de Costa Lima a esse propósito, passando pelos narrativistas anglo-americanos, White e Ricœur, cotejando-os com os aspectos centrais da hipótese de Lawrence Stone. Especificamente acerca das críticas de Costa Lima a White quanto ao potencial narrativo dos anais medievais, Benzaquen pondera que não se trata de privilegiar uma ordem político-social em detrimento de outra, no caso "cosmo-teológica", mas que essa última não seria capaz de conferir "no nível do próprio texto" uma "articulação específica dos eventos humanos". Invertendo a conclusão de Costa Lima, Benzaquen argumenta que "talvez se pudesse indicar que é precisamente por supor uma explicação de fundo religioso, misterioso, 'inacessível à pobre razão humana' [frase de Costa Lima], que os anais afastam-se do modelo da narrativa, pelo menos desta narrativa escrita e moderna" (ARAÚJO 1988a, p. 102). Além disso, o comentador chama a atenção para a cautela que se deve ter a fim de não se naturalizar a vinculação do modo narrativo de escrita da história - "seu caráter singular, contextualizado, não universal" - a um "centro social" ou "ao mundo das nações", sobretudo em se tratando do século XIX, evitando-se, dessa forma, a manipulação ou a instrumentalização da história (ARAÚJO $1988 a$, p. 102). ${ }^{33}$

Em relação ao debate sobre o retorno da narrativa, Benzaquen afirma:

boa parte dos trabalhos que compõem este revival acabam, pelo menos até certo ponto, por se distanciar de um compromisso absoluto com a totalidade, com uma exigência que lhes impusesse a construção de uma imagem coerente, exaustiva e sistemática da sociedade que estudam (ARAÚJO 1988a, p. 108).

Portanto, segue o comentador,

não é raro que suas análises possam dar a impressão de que falta "alguma coisa", criando um clima de inacabamento e indeterminação que talvez aproxime esta nova narrativa de uma determinada concepção de ensaio. [...] Se essas especulações vierem a ser confirmadas, o revival da narrativa terá então um alcance e um significado maiores do que podíamos inicialmente supor (ARAúJO 1988a, p. 108-109, grifos meus).

O retorno à narrativa poderia ser responsável por "certa mudança no ethos do historiador", uma vez que os historiadores habitualmente empenhados na busca da verdade, dos fatos e das estruturas, tiveram sempre uma inclinação "pela transparência e pela limpidez, desprezando as possibilidades oferecidas pela polêmica, pelo confronto, por uma continua problematização" (ARAúJO $1988 a$, p. 109). Finalmente, dessa forma se ampliaria "o espaço reservado à ironia para que ela possa conviver com uma certa medida de ceticismo" (ARAÚJO 1988a, p. 109). Agora, a figura gêmea do espectro, sob efeito controlado, parece ir ao encontro de certo neopirronismo como alternativa

\footnotetext{
33 "Ela [a narrativa] precisa ser minimamente qualificada, até porque corremos o risco de que se imagine que o relato histórico servisse apenas para a glorificação dos estados nacionais, como se o relato histórico fosse meramente uma peça de propaganda ou algo parecido" (ARAÚJO 1988a, p. 102-103).
} 
para a reflexão histórica. Não custa relembrar o título do comentário de Benzaquen: "As almas da história"! 34

Um ano após o evento do Rio de Janeiro, em 1988, no primeiro volume da revista Estudos históricos, em um dossiê significativamente intitulado "Caminhos da historiografia", Manoel Salgado Guimarães e o próprio Ricardo Benzaquen Araújo publicam artigos que se tornarão fontes de inspiração para a história da historiografia e para a reflexão, à revelia deles, dos efeitos do giro linguístico entre nós (GUIMARÃES 1988; ARAúJO 1988b). Contudo, não é possível neste momento realizar uma análise mais pormenorizada. ${ }^{35}$ Apenas fazemos um breve comentário sobre cada um deles. O primeiro artigo "Nação e civilização nos trópicos: o Instituto Histórico e Geográfico Brasileiro e o projeto de uma história nacional", de Manoel Salgado Guimarães, como sabemos, é um resumo de sua tese apresentada um ano antes na Universidade de Berlim. A questão da escrita da história é estudada a partir de pressupostos que envolvem a semântica histórica de Koselleck, ancorada na leitura de Michel de Certeau e de Foucault, sem, entretanto, unificar esses autores artificialmente, mas servindo-se deles como instrumentos teóricos para pensar a narrativa historiográfica. Não se trata de cópia de modelos teóricos estrangeiros, mas de diálogo com outras culturas historiográficas.

Já o texto de Benzaquen, "Ronda noturna: narrativa, crítica e verdade em Capistrano de Abreu", reivindica explicitamente a contribuição de Hayden White (bem como as de Costa Lima, Koselleck, Momigliano, Ricœur, Benjamin) e, a partir dele (ou deles), a questão de fundo que emerge é a da objetividade histórica e seus modos:

[...] resta ainda a discussão do próprio tema da objetividade, ou seja, resta indagarmos como e por que o ideal de uma disciplina absolutamente realista e imparcial adquiriu tal prestígio entre os praticantes da concepção moderna de história que, com frequência, mal percebem o caráter "informado" das formulações que, quase como "aprendizes de feiticeiro" acostumaram-se a utilizar (ARAÚJO 1988b, p. 53).

E, na nota correspondente a esta afirmação (n. 15), o autor explica:

Se, de vez em quando, aprendizes de feiticeiro acertam a fórmula de transformar chumbo em ouro, creio que vale a pena assinalar que só muito recentemente, depois da "escola dos Anais" e de uma certa articulação da historiografia com a tradição sociológica, de um lado, e com a teoria literária, de outro, foi que se começou a encontrar historiadores dispostos a discutir de forma mais ampla o alcance e a profundidade dos seus

\footnotetext{
34 No debate realizado na PUC-Rio, em 2013, tive a oportunidade de perguntar a Ricardo Benzaquen Araújo pela razão exata do título. Resposta: "para guardar a pluralidade do conceito de história". Fiquei para lá de satisfeito! 35 Provavelmente, os grandes ausentes brasileiros desta análise sejam Arno Wehling e Afonso Carlos Marques dos Santos, cujos primeiros escritos se inserem neste contexto. Por razões distintas parece-me que ambos sinalizam para outro corte de recepção que não o do giro linguístico. Enquanto o primeiro participa de um movimento mais amplo da cultura historiográfica no qual a filosofia da história é um fator relevante na definição de códigos disciplinares e científicos (WEHLING 1994), o segundo, a meu ver, estaria mais próximo do que poderíamos chamar, na ausência de uma definição mais qualificada, de um engajamento erudito. Daí a relevância de autores como Cornelius Castoriadis, Michel Foucault e Paul Veyne em suas pesquisas, muito mais do que de Hayden White, por exemplo (SANTOS 2007). Agradeço a Valdei Lopes de Araujo por ter me apontado essa omissão. A propósito, seu artigo - "O século XIX no contexto da redemocratização brasileira: a escrita da história oitocentista, balanços e perspectivas" - é, nesse sentido, revelador, independentemente de sua concordância com meu argumento (ARAUJO 2012).
} 
pressupostos. Acerca desta "mutação historiográfica", pode-se procurar para uma primeira abordagem os trabalhos de Furet, 1982, e de White, 1984 (ARAÚJO 1988b, p. 53).

Houve, assim, um "impacto" (resguardando aqui as limitações analíticas e metodológicas mencionadas anteriormente) do giro linguístico no Brasil. É necessário que se realizem mais estudos para avaliar sua dimensão e consequências efetivas. Não basta acusá-lo de relativista, irracional ou de ceticismo, nem, simplesmente, negar a importância das formas da objetividade ou de objetivação do conhecimento histórico, entre as quais se inclui a própria ideia de verdade, cuja duração não se reduz aos últimos 40 anos. ${ }^{36}$

\section{(In)determinação e (in)certezas cartesianas}

Sem querer ser prescritivo, por fim, não seria interessante colocarmo-nos um pouco na posição daquele Hamlet intelectual? Quem seria ou o que seria um Hamlet brasileiro? Uma pessoa? Várias? Uma corporação? Uma configuração epistemológica? Como meditarmos sobre a vida e a morte das verdades e fantasmas originados pelas nossas controvérsias? Difícil responder. Não obstante, gostaria de evocar dois poetas contemporâneos e, assim, tentar nos reaproximar do clima histórico marcado pela instabilidade, que, ao mesmo tempo, assusta e incita, e que talvez possa nos dar algumas pistas, além de nos reaproximar de um indisfarçável desejo aristotélico, contido na obra de Hayden White, de reunir poesia e história (WHITE 2010a, p. XI).

Ambos relacionam-se, paradoxalmente, não a Aristóteles, mas a Descartes. Primeiro, imaginemos Descartes no Brasil acompanhando a comitiva de Maurício de Nassau, que se instalava em Recife no século XVII. Paulo Leminski, em 1966, em uma aula de história do Brasil, teve exatamente esse insight. Um Descartes Renatus Cartésius - nos trópicos! Catatau, a obra que trata dessa impossibilidade, foi publicada em edição independente em 1975, em plena ditadura civil-militar: "O Catatau é o fracasso da lógica cartesiana branca no calor" (LEMINSKI 1989, p. 208). ${ }^{37}$ Seria uma metáfora concretista de seu tempo presente? Como ser claro e distinto em meio a obtusos generais? Nada, contudo, autoriza-nos, em princípio, a tal interpretação; salvo, talvez, o tempo transcorrido e a forte tendência que dele decorre, da qual não estou inteiramente imune, e que leva os historiadores, consciente ou inconscientemente, a associar, de alguma maneira, toda e qualquer experiência artística, de vanguarda ou contracultural, à grande história política. Como se a descontinuidade fosse um bloqueio para a compreensão e não uma de suas formas de expressão. Logo, se aqui ou hoje, como lá e ontem, o Catatau (a) parece (como) um exemplo da instabilidade da palavra, do texto que perturba,

\footnotetext{
36 "Dificilmente se encontrará um historiador que não almeje padrões de objetividade para seu conhecimento. Hoje, contudo, estão em jogo diversas opções de entendimento sobre o que seja tal objetividade, ou quais níveis de objetividade são possíveis serem atingidos em cada caso. São problemas teóricos complexos, maiores do que as antigas discussões sobre a possibilidade ou impossibilidade de um conhecimento histórico científico. Não enfrentá-los é retardar, ainda mais, a incorporação das discussões suscitadas pelas descobertas sobre o indeterminismo, sobre a relatividade e sobre as discrepâncias observáveis em diversos níveis do real" (FICO 1994, p. 115).

${ }^{37}$ Agradeço vivamente a Henrique Estrada por me lembrar a pertinência do Catatau para meu argumento.
} 
da incerteza que desestrutura a ordem intelectual, então não seria um exagero pensar esse "romance-ideia", na definição de seu autor, como uma espécie de manifestação estética que simboliza a indeterminação que tenho buscado apontar como indicador das possibilidades de se pensar a história da historiografia neste contexto do giro linguístico: "a lógica não é limpa, como pretende a Europa, desde Aristóteles. A lógica deles, aqui, é uma farsa, uma impossibilidade". O Catatau não apenas quer superar essa lógica como "lançar bases de lógica nova". Ele quer ser um tipo de entremeio entre "a eterna inadequação dos instrumentos consagrados, face à irrupção de realidades inéditas" (LEMINSKI 1989, p. 211). ${ }^{38}$

Já o Sr. Cogito é uma pessoa mais comum, um pouco como o Ulrich de Robert Musil, talvez apenas menos contemplativo, que, com o passar dos anos, converte a experiência do cotidiano em questões claras e distintas sobre a existência, para fazer jus à premissa cartesiana de seu nome. Personagem de inúmeras poesias do polonês Zbigniew Herbert, O Sr. Cogito teria surgido em 1974. Em um desses poemas, significativamente intitulado Mr Cogito on the Need for Precision, ele declara: ${ }^{39}$

Um espectro ronda

o mapa da história

o espectro da indeterminação

quantos gregos pereceram em Troia

Nós não sabemos (HERBERT 2007, p. 404-408).40

\subsection{Referências bibliográficas}

ANKERSMIT, Frank. The linguistic turn: literary theory and historical theory. In: Historical representation. Stanford: Stanford University Press, 2001.

ARAÚJO, Ricardo Benzaquen de. As almas da história - Cometário. In: RIEDEL, Dirce Côrtes (org.). Narrativa, ficção \& história. Rio de Janeiro: Imago, 1988a, p. 90-111.

- Ronda noturna: narrativa, crítica e verdade em Capistrano de Abreu. Estudos históricos, n. 1, p. 28-54, 1988b.

ARAUJO, Valdei Lopes de. O século XIX no contexto da redemocratização brasileira: a escrita da história oitocentista, balanços e perspectivas. In: OLIVEIRA, Maria da Glória de; ARAUJO, Valdei Lopes de. (orgs.) Disputas pelo passado: história e historiadores no Império do Brasil. Ouro Preto: Edufop/PPGHIST, 2012.

\footnotetext{
${ }^{38}$ Referência válida também para as duas citações anteriores.

39 Agradeço a Paulo Faria, colega do Departamento de Filosofia da UFRGS, que há alguns anos me chamou a atenção para a obra de Zbigniew Herbert.

$40 \mathrm{Sr}$. Cogito e a necessidade de precisão. No original: A specter is haunting /the map of history/the specter of indeterminacy/how many Greeks perished at Troy/- we don't know" (tradução minha, revisão de Marina Araújo, a quem também devo a tradução do Abstract). Por coincidência, Troia também assombra o Catatau de Leminski: "Lembro do mapa, neste mapa falta Tróia mas Tróia não faz falta. [...] Por que esse medo de dizer Tróia, estória, destroyão? [...] Pleiteio uma empreitada, a estreita emboscada, introito in Tróia" (LEMINSKI 1989, p. 50, 63, 95). A aparente insignificância de Troia não dissimula, entretanto, a importância da presença do jogo da indeterminação histórica.
} 
ARENDT, Hannah. Entre o passado e o futuro. São Paulo: Perspectiva, 1992.

BARTHES, Roland. Le discours de I'histoire. In: Bruissement de la langue. Paris: Seuil, 1984, p. 163-177.

CALDAS, Pedro Spinola Pereira. Para além do giro-linguístico: uma abordagem existencialista da obra de Hayden White. História da historiografia, $\mathrm{n}$. 11 , p. 272-278, 2013.

CAMARGO, Aspásia. Entrevista François Furet concedida a Aspásia Camargo. In: OLIVEIRA, Lúcia Lippi; FERREIRA, Marieta de Moraes; CASTRO, Celso. Conversando com... Rio de Janeiro: Ed. da FGV, 2003.

CARDOSO, Ciro Flamarion. Uma introdução à história. São Paulo: Brasiliense, 1981.

. Uma "Nova História"? In: Ensaios racionalistas. Campus: Rio de Janeiro, 1988.

. Um historiador fala de teoria e metodologia. Ensaios. Bauru: Edusc, 2005.

; VAINFAS, Ronaldo (orgs.). Domínios da história: ensaios de teoria e metodologia. Rio de Janeiro: Campus, 1997.

Campus, 2012.

(orgs.). Novos domínios da História. Rio de Janeiro:

CARR, David. Time, narrative and history. Blooming : Indiana University Press, 1991.

CERTEAU, Michel de. Une épistémologie de transition: Paul Veyne. Annales, n. 6, p. 1317-1327, 1972.

. L'absent de I'histoire. Paris : Maison Mame, 1973.

. L'écriture de I'histoire. Paris: Gallimard, 1975.

Histoire et psychanalyse entre science et fiction. Paris : Gallimard, 1987.

CUNHA, Maria Clementina Pereira. O espelho do mundo: Juquery, a história de um asilo. Rio de Janeiro: Paz e Terra, 1987.

DANTO, Arthur. Analytical philosophy of Science. Cambridge: Cambridge University Press, 1965.

DECCA, Edgar de. O silêncio dos vencidos. São Paulo: Brasiliense, 1981.

DELACROIX, Christian. Linguistic turn. In : DELACROIX, C. ; DOSSE, F.; GARCIA, P.; OFFENSTADT, N. Historiographies, I. Concepts et débats. Paris: Gallimard, 2010, p. 476-490.

DERRIDA, Jacques. De la grammatologie. Paris: Les Éditions de Minuit, 1967.

. Espectros de Marx. Rio de Janeiro: Relume-Dumará, 1994.

DRAY, William. On the Nature and Role of Narrative in Historiography. History and theory, v. 10, n. 2, p. 153-171, 1971. 
DOSSE, François. L'histoire en miettes: des "Annales" à la "nouvelle histoire". Paris: Gallimard, 1987.

FICO, Carlos. Alguns impasses da produção historiográfica recente no Brasil. Anos 90, n. 2, p. 111-126, maio 1994.

- Algumas anotações sobre historiografia, teoria e método no Brasil dos anos 1990. In: GUAZZELLI, Cesar A. B. et alii (orgs.). Questões de teoria e metodologia da história. Porto Alegre: Ed. da Universidade/ UFRGS, 2000, p. 27-40.

; POLITO, R. A história no Brasil (1980-1989): elementos para uma avaliação historiográfica. V. 1. Ouro Preto: UFOP, 1992.

FURET, François. L'atelier de I'histoire. Paris: Flammarion, 1982.

GUIMARÃES, Manoel Salgado. Nação e Civilização nos Trópicos: o Instituto Histórico e Geográfico Brasileiro e o projeto de uma História Nacional. Estudos Históricos, n. 1, p. 5-27, 1988.

GINZBURG, Carlo. Just one Witness. In: FRIEDLANDER, Saul (ed.). Probing the limits of representation: nazism and the "final solution". Cambridge: Harvard University Press, 1992, p. 82-96.

Provas e possibilidades à margem de "Il ritorno de Matin Guerre", de Natalie Zemon Davis. In: . A micro-história e outros ensaios. Lisboa: Difel, 1989, p. 178-220. . Montrer et citer. La vérité de l'histoire. Le Débat, n. 56, p. 44-45, 1989. Le juge et I'historien. Lagrasse: Verdier, 1997.

HARTOG, François. Régimes d'historicité, présentisme et expérience du temps. Paris: Seuil, 2003.

. Le regard éloigné: Lévi-Strauss et I'histoire. In: Évidence de

I'histoire: ce que voient les historiens. Paris : Éd. de I'EHESS, 2005, p. 175-189.

Croire en I'histoire. Paris: Flammarion, 2013.

HERBERT, Zbigniew. The collected poems (1956-1998). New York: HarperCollins Publishers, 2007.

KOSELLECK, Reinhart. Introduction to Hayden White's Tropics of discourse. In: . The practice of conceptual history: timing history, spacing concepts. Stanford: Stanford University Press, 2002.

LA CAPRA, Dominick; KAPLAN, Steven (eds.). Modern European intellectual history: reappraisals \& new perspectives. London: Cornell University Press, 1982.

LIMA, Luiz Costa. Clio em questão: a narrativa na escrita da história. In: RIEDEL, Dirce Côrtes (org.). Narrativa, ficção \& história. Rio de Janeiro: Imago, 1988, p. 63-89. 
. História. Ficção. Literatura. São Paulo: Companhia das Letras, 2006. Trilogia do controle: o controle do imaginário. Sociedade e discurso ficcional. O fingidor e o censor. Rio de Janeiro: Ed. Topbooks, 2007.

MINK, Louis. The autonomy of historical understanding. History and theory, v. 5, n. 1 , p. 24-47, 1966.

. History and fiction as modes of comprenhension (1970). In: COHEN, Ralph (ed.). New directions in literary history. London: Routledge \& Kegan Paul, 1974, p. 107-124.

MUNSLOW, Alun. Deconstructing history. London and New York: Routledge, 1997.

The future of history. New York : Palgrave MacMillan, 2010.

NOIRIEL, Gérard. Sur la "crise" de l'histoire. Paris: Belin, 1996.

NORA, Pierre; LE GOFF, Jacques. (dir.). Histoire. T. 1 - Nouveaux problèmes ; t. 2 - Nouvelles approches; t 3 - Nouveaux objets. Paris: Gallimard, 1974.

PALTI, Elias José. "Giro lingüístico" e historia intelectual. Buenos Aires: Universidad Nacional de Quilmes, 1998.

PAUL, Herman. Hayden White: the historical imagination. Cambridge: Polity Press, 2011.

PETERSEN, Sílvia. Algumas interrogações sobre as tendências recentes da historiografia brasileira: a emergência do novo e a crítica ao racionalismo.

Revista de história, v. 3, n. 1, p. 108-126, 1992a.

- Dilemas e desafios da historiografia brasileira: a temática da vida cotidiana. História e perspectivas, v. 6, p. 24-44, 1992b.

Michel Maffesoli: um teórico da vida cotidiana. Biblos, Rio Grande, v. 5, 1993, p. 41-55.

A renovação da historiografia e a temática da vida cotidiana: desfazendo alguns equívocos. In: $\mathrm{MAUCH}$, Claudia (org.) Porto Alegre na virada do século XIX: cultura e sociedade. Porto Alegre: Editora da Universidade/ UFRGS, 1994, p. 112-25.

. O cotidiano como objeto teórico ou o impasse entre ciência e senso comum no conhecimento da vida cotidiana. MESQUITA, Zilá; BRANDÃO, Carlos R. (orgs.). Territórios do cotidiano: uma introdução a novos olhares e experiências. Porto Alegre: Ed. da Universidade da UFRGS/ EDUNISC, 1995, p. 30-39.

PIRES, Francisco Murari. Indagações sobre um método acima de qualquer suspeita. História da Historiografia, n. 13, p. 24-44, 2013.

POPKIN, Richard. The history of skepticism: From Savonarola to Bayle. Oxford: Oxford University Press, 2003.

RAGO, Margareth. Do cabaré ao lar. Rio de Janeiro: Paz e Terra, 1985. 
ROBIN, Régine. Histoire et linguistique. Paris: Armand Colin, 1973.

RORTY, Richard. The linguistic turn: essays in Philosophical Method. Chicago, London: University of Chicago Press, 1967.

RICCFUR, Paul. Temps et récit. Tome I: L'intrigue et le récit historique. Paris: Éd. Seuil, 1983.

Temps et récit. Tome III: Les temps raconté. Paris: Éd. Seuil, 1985.

ROUANET, Sérgio Paulo. O novo irracionalismo brasileiro. In: As razões do Iluminismo. São Paulo: Companhia das Letras, 1987, p. 124-146.

SANTOS, Afonso Carlos Marques. A invenção do Brasil: ensaios de história e cultura. Rio de Janeiro: Editora da UFRJ, 2007.

SEARLE, John. Pour réitérer les différences, réponse à Derrida. Paris: L'éclat, 1991.

SEVCENKO, Nicolau. Literatura como missão: tensões sociais e criação cultural na Primeira República. São Paulo: Brasiliense, 1983.

SKINNER, Quentin (ed.). The return of grand theory to the human sciences. Cambridge: Cambridge University Press, 1985.

SOUZA, Laura Melo de. O diabo e a Terra de Santa Cruz: feitiçaria e religiosidade popular no Brasil colonial. São Paulo: Companhia das Letras, 1986.

460 spIEGEL, Gabrielle. History and post-modernism. Past and present, n. 135, p. 189-208, 1992.

. The task of the historian. Presidential address delivered at the $123 \mathrm{rd}$ annual meeting of the American Historical Association, held in New York City in 2009. Disponível em: http://www.historians.org/about-aha-andmembership/aha-history-and-archives/presidential-addresses/gabriellem-spiegel. Acesso em: 7 ago. 2014.

STONE, Laurence. The revival of narrative. Reflections on a new old history. Past and present, n. 85, p. 3-24, 1979.

VALÉRY, Paul. Essais quasi politiques. In: Cuvres. Paris: Gallimard, 1957. (Bibl. De la Pléiade, t. I).

VANN, Richard T. Turning Linguistic: History and theory and History and theory, 1960-1975 In: ANKERSMIT, Frank; KELLNER, Hans (eds.). A new philosophy of history. London: Reaktion Books, 1995, p. 40-69.

. The Reception of Hayden White. History and theory, v. 37, n. 2, p. 143-161, 1998.

VEYNE, Paul. Comment on écrit I'histoire: essais d'épistémologie. Paris: Seuil, 1971.

WEHLING, Arno. A invenção da história: estudos sobre o historicismo. Rio de Janeiro: Ed. Central; Niterói: Ed. UFF, 1994. 
WHITE, Hayden. The Greco-Roman tradition. New York: Harper \& Row, 1973. . The politics of historical interpretation: discipline and de-sublimation. In: . The content of form: narrative discourse and historical representation. Baltimore and London: The Johns Hopkins University Press, 1987.

. Historical emplotment and the problem of truth. In: FRIEDLANDER, Saul (ed.). Probing the limits of representation: nazism and the "final solution". Cambridge: Harvard University Press, 1992, p. 37-53.

. Trópicos do discurso: ensaios sobre a crítica da cultura. São Paulo: Edusp, 1994.

The fiction of narrative: essays on history, literature and theory (1957-2007). Edited and with an introduction by Robert Doran. Baltimore: The Johns Hopkins University Press, 2010a.

. Ficción histórica, historia ficcional y realidad histórica. Introducción de Verônica Tozzi. Buenos Aires: Prometeu Libros, 2010b.

ZAIDAN FILHO, Michel. A crise da razão histórica. Campinas: Papirus, 1989. 